\title{
Literary and biographical perspectives on substance use
}

\section{Ed Day \& Iain Smith}

\begin{abstract}
This article attempts to give a flavour of the influence that psychoactive substances have had on many authors and the literary process. It explores the idea of the narrative as it is applied to addictive disorders and gives a range of examples of writing about different substances that might enhance the reader's knowledge of current drug culture. The portrayal in literature of doctors with addictions is presented as a warning against the development of such problems in psychiatrists. The authors hope to have demonstrated that literature can be a valuable tool in understanding the experience of drug and alcohol use and addiction.
\end{abstract}

This is the second in a series of papers on literature and psychiatry. The previous paper (Eynon, 2002) introduced cognitive linguistics and metaphor. Future papers will consider, among other things, how dementia is described in fiction and biography, the value of autobiographical narrative to psychiatry and the description of death and dying in English literature.

The effects of psychoactive drugs have been closely linked to all forms of literature for as long as humans have been writing, but a review of the subject is currently very topical. Although the problems of alcohol have long been a theme covered by authors, other drugs have not been as well represented in mainstream publishing until the past few decades. However, the escalation of the drug problem in the Western world has had an influence on popular fiction and led to a rekindling of interest in an older literature that explored these themes. The work of the 19th-century Romantics and of the Beat Generation and counter-culture of the 1960s has been developed by the 'chemical generation', with ecstasy (methylenedioxymethamphetamine (MDMA)) joining the opiates, cocaine, cannabis, lysergic acid diethylamide (LSD) and amphetamines as a backdrop to popular fiction.

\section{Writers and alcohol}

Alcohol, in particular, as been strongly linked to creativity, and John Sutherland, a professor of English literature in London and a self-confessed 'recovering drunk', has written extensively in this area. His book Last Drink to LA (Sutherland, 2001) provides some literary signposts on the path to understanding alcohol addiction and describes his own experiences at Alcoholics Anonymous (AA). Through his attendance at AA meetings, Sutherland has come to see addicts primarily as storytellers, believing that 'telling tales (most of them tall, many of them self-serving) is one of the few things that booze makes you good at' (Sutherland, 2001: p. 73).

Analysis of the lives of many famous writers reveals evidence of heavy alcohol consumption, mental illness, physical disease, family breakdown, suicide and premature death (Post, 1994). There has been much interest in the link between alcohol and writing in the USA, particularly since the realisation that five of the first seven American-born writers awarded the Nobel Prize for Literature had alcoholrelated problems (Sinclair Lewis, Eugene O'Neill, William Faulkner, Ernest Hemingway and John Steinbeck). However, it is the case of one name omitted from this list, that of F. Scott Fitzgerald, which illustrates some of the possible reasons for the link between writing and drinking alcohol (Box 1) - a source of speculation for academics and psychiatrists alike (Goodwin, 1988; Dardis, 1989).

There is a belief that creative people are expected to have a significant flaw in their character and that this is an integral part of their creativity. Baudelaire (Bond, 1982: p. 87) believed that intoxication was essential to creativity and Nietzsche agreed, stating

Ed Day is a specialist registrar in addiction psychiatry and an honorary lecturer in psychiatry at the University of Birmingham's Addictive Behaviours Centre (120-122 Corporation Street, Birmingham B4 6SX, UK). He is a member of the Royal College of Psychiatrists' Substance Misuse Faculty Executive Committee. His research interests include opiate detoxification and addiction in older adults. Iain Smith is a consultant psychiatrist and honorary clinical senior lecturer at Glasgow University. He is the Training Programme Director for the West of Scotland General Adult Psychiatry Specialist Registrar Rotation and a member of the College's Substance Misuse Faculty Executive Committee. His research interests include alcohol-related brain damage and the history of psychiatry. 


\section{Box 1 The case of F. Scott Fitzgerald}

F. Scott Fitzgerald was both a creator and chronicler of the 'Roaring Twenties' in America and he achieved fame and fortune at a young age for his unique writing style. Born in 1896, by the age of 24 he was selling stories to a national newspaper for $\$ 2500$ and his ability to turn out high-quality pieces enabled him to earn the money to maintain a lavish lifestyle of parties and drinking. Early in his career, Fitzgerald tried to keep drinking and writing separate and he abstained from alcohol while writing his most famous novel, The Great Gatsby (Fitzgerald, 1993). However, by the late 1920s, he was beginning to feel the pressure of producing a follow-up to Gatsby and rounds of all-night parties repeatedly forced him to abandon plans for writing a new novel in favour of producing short stories to sell.

From 1928 he was beginning to use alcohol to assist his writing, regarding it as a stimulant that would fuel his creative powers. However, it seems that he was aware of the problems that it caused him, writing that 'a short story can be written on the bottle, but for a novel you need the mental speed that enables you to keep the whole pattern in your head' (Dardis, 1989: p. 123).

In 1931 he moved to Hollywood to work as a scriptwriter and, although this earned good money, he was ultimately sacked for drunken behaviour at a party. He began to find it difficult to sell his stories and 1933 saw his first alcohol-related admission to hospital. Still he continued to drink and when his next novel, Tender is The Night (Fitzgerald, 1994), was finally published in 1934, it fell below the standards expected of him. Critics agreed that the man who began the book in 1925 was not the same man that finished it in 1933 and Fitzgerald himself believed that alcohol had marred the work (Dardis, 1989).

In 1936, he wrote three short articles for a magazine that described his emotional collapse (which were ultimately published under the title The Crack-Up; Fitzgerald, 1965), but he avoided any mention of alcohol. The following year he took an overdose but managed to return to another job in Hollywood, which gave him the inspiration for his final (unfinished) novel, The Last Tycoon (Fitzgerald, 2002).

In the last decade of his life, Fitzgerald experienced worsening physical problems related to alcohol and underwent frequent hospital admissions; insomnia and morning drinking became regular and disabling parts of life. He finally died of a myocardial infarction in 1940, aged just 44 (Dardis, 1989).

that 'for art to exist, for any sort of aesthetic society or perception to exist, a certain physiological precondition is indispensable: intoxication' (Marks, 2001: p. 506 ${ }^{1}$. In the early 1920s, Fitzgerald was prone to introduce himself to people at parties as an alcoholic, a tactic apparently designed to shock. Many writers comment on their use of alcohol to help them to relax after an intense period of work. Ernest Hemingway, a close friend of Fitzgerald, had a regular routine each day whereby he would get up early, write in the morning, fish or hunt in the afternoon and drink to relax and unwind in the evening. Both he and William Faulkner said that they used alcohol to help them stop writing: to switch off the creative process.

Alcohol may give writers confidence and help them to overcome what Georges Simenon called 'stage fright': the doubts about their ability to write and the quality of their work (Goodwin, 1988: p. 186). Some writers have stated that alcohol improved their writing ability, and Fitzgerald felt that stories he wrote while sober seemed 'stupid' and 'all reasoned out, not felt' (Goodwin, 1988: p. 187). Other, more contemporary, authors have agreed with Stephen King, believing that 'a writer

1. Books are not necessarily referenced to their first editions. who drinks carefully is probably a better writer' (Goodwin, 1988, p. 187). However, sustained use of alcohol appears to have accelerated a decline in Fitzgerald's standard of both writing and health, as it did with contemporaries such as William Faulkner.

From a medical perspective, it is easy to view the life of Fitzgerald and others as being destroyed by alcohol. However, as Beveridge \& Yorston (1999) point out, writers and artists have often seen the role of alcohol very differently. Alcohol has formed part of religious practices and customs for thousands of years and is often seen as an agent of mystical transport (Edwards, 2000). Writers such as Malcolm Lowry and Jack Kerouac have cited it as a means of spiritual exploration and a way of seeking enlightenment. Furthermore, bad behaviour by writers has been seen as a symbol of rebellion, and drinking has often formed an integral part of literary scenes, where it has acted as a symbol of rebellion against contemporary values. There is the added advantage that an alcoholic low-life is seen as especially conducive to the creative process and that some must experience degradation to produce great work. A striking example of this was Charles Bukowski who, in addition to his poetry, wrote a string of semiautobiographical novels about his impoverished early life and his time spent drinking heavily in seedy bars. His ultimate elevation to being rich and 
famous appears to have vindicated his life of excessive drinking and bad behaviour (Sounes, 1998).

Donald Goodwin (1988) believes in the idea that writers are introverted and lonely people, tortured souls that can express their overload of feelings only through writing. The artist has often been portrayed as someone who is especially aware of the suffering of the world and needs to numb himself or herself to cope. Such a perspective allows an unlimited licence for hedonistic excess, leading to a long list of writers who died prematurely, for example Dylan Thomas, Brendan Behan, Jack Kerouac, Malcolm Lowry and Fitzgerald himself.

However, the final piece in the jigsaw may come from a study conducted by Nancy Andreasen (1987). She rated a group of writers attending a creative writing workshop and a control group of nonwriters (matched for age, gender, education and intelligence) using the research diagnostic criteria (RDC). The writers had significantly higher levels of bipolar disorder and alcoholism than the control group, 24 out of 30 having experienced an affective disorder at some point in their life.

Felix Post's work has also concluded that, in contrast with people showing other kinds of creative achievement, creative writers are excessively prone to depressive and perhaps to manic disorders, as well as to alcoholism (Post, 1994). In a study focusing on those writing poetry, fiction and plays, Post found evidence of psychopathology in the biographies of 93 out of 100 individuals (Post, 1996). These studies point to a link between creative verbal ability and affective as well as related psychopathology, and this might be the underlying basis that links creativity and alcohol dependence.

\section{Addiction and the art of writing}

The idea that psychoactive substances are linked to creativity goes beyond the writers themselves to the way in which they produced their work. From the Romantic poets of the 18th century to the Beat Generation of the mid-20th century, drugs have long been reputed to be central to the literary process. Several specific examples have been given of the direct role that opium played in the creation of literary works of the 18th and 19th centuries (Hayter, 1968). At this time, the drug was widely available throughout Europe and a variety of preparations could be bought over the counter. Laudanum, a drink consisting of opium mixed with alcohol, was particularly popular and many people used it as an effective means of pain relief. Opium carried with it a seductive air of Far Eastern mystique and its 'specific power' to enhance dreams and memories appealed to many writers (Plant, 1999).
Perhaps the most famous example of opiuminduced creativity is Kubla Khan (Coleridge, 1992), a poem written by Samuel Taylor Coleridge in the late 1790s. Coleridge called the poem 'a psychological curiosity' (Plant, 1999: p. 10) and claimed that it was a fragment of a much longer sequence that came to him in a dream induced by a dose of opium. Originally, the poem consisted of 200-300 lines, but when he woke up and began to write it down 'a person on business from Porlock' (Plant, 1999: p. 10) interrupted him. This was enough to break his flow and, on returning to the poem, he was left with only eight or ten lines and images. The fact that he later tried to recreate the situation without success did not deter others from experimenting with the drug.

In Sadie Plant's words, 'poets were enchanted by the possibility that such poetry could spring from the opiated edge of waking life' (Plant, 1999: p. 11). Mary Shelley's Frankenstein (Shelley, 1992) is another well-known story to have emerged in a similar way and The Bride of Lammermoor by Sir Walter Scott is also reputed to have been dictated while he was taking large doses of laudanum for severe stomach pain (Scott, 1998). Alethea Hayter cites further examples in her book Opium and the Romantic Imagination (Hayter, 1968).

Wilkie Collins was one of the most popular authors of the mid- to late-19th century. For many years, he suffered from painful physical complaints, including gout and pains in the eyes, and had used laudanum regularly for at least 20 years before he wrote his novel The Moonstone (Collins, 1999). He is reported to have dictated the last part of the book largely under the influence of opium, and it is commented that when it was finished he was not only 'pleased and astonished' at the finale, but 'did not recognise it as his own' (Hayter, 1968: p. 259). The finale is particularly significant, as the plot has a central role for the drug. The book is about the theft of a large diamond (the Moonstone) by a man under the influence of opium who is left with no memory of his actions. Only when the scene is recreated does he find himself remembering what he has done. Opium clearly played a significant part in the author's life and it also appears in some of his other novels, including No Name, The Woman in White and Armadale (Collins, 1994, 1995, 1998 respectively).

However, perhaps the most famous writer of the time using opiates was Thomas De Quincey. He wrote extensively about the use of the drug in his book Confessions of an English Opium Eater (De Quincey, 1986). Here, he described the magical effects that opium had on him, allowing him to slow things down and to enhance his dreams with his own fantasies.

He described a 'Dark Interpreter', a figure that allowed him to keep track of the thoughts that were 
arranging and rearranging themselves in his head. At first he was delighted by the drug's effects, but his deficit of dreams prior to using it became a surfeit and he found it difficult to cope with them. The sheer volume and complexity of these dreams became almost unbearable and his mind was invaded by 'flashback anticipations, sudden recollections and unpredicted twists' (Plant, 1999: p. 14).

Although De Quincey's descriptions of his dreams of oriental travel enthralled his readers when they were published, to him they became terrible nightmares. He lost the ability to distinguish between an increasingly hallucinatory waking life and the intensity of opiated dreams. He felt that his audience failed to understand the sheer intensity of these dreams, the terrifying worlds onto which his doors of perception could open.

More-contemporary examples of the influence of psychoactive substances on writing include On the Road by Jack Kerouac (2000), which was apparently written in a 3-week burst of stimulant-fuelled creativity, and William S. Burrough's (1986) The Naked Lunch. Will Self's highly original and unusual work has been linked to his much-publicised problems with alcohol and drugs. However, further reflections on these legends of drug-fuelled writing often reveal them to be at least partly enhanced by fiction. Rather like the problems that Fitzgerald, Hemingway and others found in using alcohol, very little good work appears, in reality, to have been produced under the direct influence of drugs.

Careful analysis of the manuscripts of both The Moonstone and The Bride of Lammermoor suggests that they were largely completed before or after the authors' periods of illness (Sutherland, 1998). There is also evidence from letters written by the authors that both Kerouac and Burroughs preferred to write the bulk of their work while free from drugs and the now-abstinent Will Self comments that he has 'always had to fight against them in order to get any serious literary work done' (Barber, 2000). De Quincey's florid descriptions of opium-induced behaviour certainly bear little resemblance to the experiences described by those who use the substance misuse treatment services that we run.

\section{The narratives of addiction}

An important question for the reader of any fictional portrayal of addiction is its plausibility. Recent qualitative studies have tried to make sense of the addicts' subjective experience of their own life history in relation to their problem (Hanninen \& Koski-Jannes, 1999; McIntosh \& McKeganey, 2000). One such example was based on the real-life stories of 51 individuals who had overcome some form of addiction, with the narratives influenced by the explanatory models for addiction that were available to each of them as they made their escape from dependence (Hanninen \& Koski-Jannes, 1999). The authors identified the following five types of story.

\section{The 'AA' story}

This is the least surprising, given the worldwide influence of Alcoholics Anonymous (AA) and the extension of the organisation's explanatory model to all types of compulsive behaviour in our society. The trajectory of addiction is towards destruction, with individuals beginning to gain insight only when they reach their own 'personal gutter'. At this point, they can find salvation through applying the principles of AA, a process involving humility, finding the support of fellow recovering addicts and making amends where possible. Moral absolution and self-forgiveness follow from this disease model of addiction.

\section{The 'personal growth' story}

Here the addict has had his or her wishes and emotions disregarded as a child and the addiction has arisen as a denial of the individual's own emotional needs in favour of those of others. Recovery results from recognising and following these true emotions through self-discovery.

\section{The 'co-dependence' story}

The narrative is one where repressed secrets from childhood underlie the self-abusive behaviour of addiction, and the cure relies on becoming aware of and facing up to these memories.

\section{The 'love' story}

Addictive behaviour compensates for a lack of love in childhood and a cure comes through finding love.

\section{The 'mastery' story}

This was most commonly found in relation to addiction to tobacco. It was portrayed as a battle for autonomy during the different phases of the addiction, with 'giving-up' seen as part of achieving maturity.

\section{Fiction's window on addiction}

It is more difficult to get a narrative from someone who denies his or her addiction, and this may be where fiction can add to our understanding. As one 
author has observed, 'an addiction is held in place by an elaborate system of deceptions' (Beard, 1996) and a good fictional example of this is The Legend of the Holy Drinker, written in 1939 by Joseph Roth (Roth, 2000). This novella follows the fortunes of Andreas, an alcoholic vagrant who drinks as a response to external circumstances, but with little self-realisation. It is a simple story that engenders pathos and has parallels in Roth's own life story, although it is not autobiographical. Alternative narratives are also provided by the books Junky (Burroughs, 1977) and Trainspotting (Welsh, 1999), in which the addiction and its maintenance are seen as a matter of personal choice rather than something over which the individual has no control. This is no surprise when we consider the perspective of attribution theory outlined in the work of John Booth Davies. In The Myth of Addiction he suggests that 'most people who use drugs do so for their own reasons, on purpose, because they like it, and because they find no adequate reason for not doing so' (Davies, 1997: p. xi). However, the capacity to blame the properties of the drug or external circumstances for its repeated use seems to predominate in our culture and this is reflected in much of the writing cited in this review.

A further dimension brought out in literature is the polarisation that on the one hand warns against the dangers of drugs and alcohol and on the other argues that drug experiences are life-enhancing and so are something to be sought. In the face of this dichotomy, some of the more interesting literature, such as Junky, occupies a middle ground in taking a more matter-of-fact approach. The 'harder' drugs (heroin, cocaine) are mostly represented in the scare stories, whereas the psychedelic drugs (LSD, ecstasy) fall into the life-enhancement end of the spectrum. As an example, compare Junk (Burgess, 1999) and Iced (Shell, 1993) with The Doors of Perception (Huxley, 1994) and the recent anthologies about psychedelic experiences listed in Box 2 .

It is perhaps no great surprise that most of the large number of autobiographical accounts of alcohol and drug dependence fall into the AA type of

\section{Box 2 Recently published drug anthologies}

The Drug User (Strausbaugh \& Blaise, 1991) White Rabbit (Miller \& Koral, 1995)

Psychedelia Britannica (Melechi, 1997)

Intoxication (Davidson, 1998)

Mindscapes (Melechi, 1998)

The Walls of Illusion (Haining, 1998)

Artificial Paradises (Jay, 1999)

Wildest Dreams (Rudgley, 2001)

The Howard Marks Book of Dope Stories (Marks, 2001) narrative. Anyone who has attended an AA meeting knows that it is based on the telling and retelling of life stories as a therapeutic tool. Furthermore, the fourth, fifth, eighth and ninth steps of AA's Twelve Steps imply the need to examine your own life story. There are numerous examples of famous people recounting their stories in this way. Examples include Addicted, by the footballer Tony Adams (1998) and the critically acclaimed Drinking: A Love Story, by Caroline Knapp (1996). In the latter, Knapp takes the reader through the phases of her alcoholism and outlines the help she found in AA. A key to this process was a shift from thinking that she drank because she was unhappy to considering that she was unhappy because she drank. In contrast, Ann Marlowe's How to Stop Time: Heroin from A to Z (1999) does not follow the Alcoholics/Narcotics Anonymous story, with the author declaring that her addiction was 'chosen'. The narrative is disjointed as she takes the reader through a lexicon of relevant terms and, interestingly, she describes reading Burroughs and De Quincey at a young age. Her dependence seems to be predominantly psychological rather than physical and she gives a good account of the subtle thought processes that led to her eventual choice to be drug-free.

\section{Current drug-related fiction}

It is currently possible to find the whole range of drug-related experience related in fictional form on the shelves of bookshops and especially in the book sections of popular music shops. Heroin and cocaine are the drugs most often featured but, more recently, ecstasy has come a close third and much of the most recent fiction has been influenced by the relatively new 'rave' culture. Publishers appear to be particularly drawn to novels with drug names in the title, with recent examples including Junk (Burgess, 1999), The Story of Junk (Yablonsky, 1997), Cocaine (Strongman, 1997) and The Ecstasy Club (Rushkoff, 1997). It would appear that such titles and their accompanying cover art are a sellingpoint. Anthologies drawing together work from a number of writers are a useful introduction to the topic and a number of recent examples are listed in Box 2. These books concentrate on drugs rather than alcohol and vary in the level to which they rely on fictional or semi-fictional sources alongside personal accounts and scientific writings on the effects of drugs. There is clearly a market for such anthologies in the era of 'recreational drug use', although they do demonstrate some of the difficulties of communicating in writing the intensity and personal nature of drug experience. Similar books about alcohol are harder to find but The Faber Book of Drink, Drinkers and Drinking (Rae, 1991) is broad in its 
coverage, with quotations from many famous literary works, and Drink to Me Only - The Prose (and Cons) of Drinking (Bold, 1982) covers the same ground more succinctly.

Few writers can have been as closely linked to the use of psychoactive drugs as William S. Burroughs, and his works such as The Naked Lunch (1986) and Junky (1977) openly reflect his addiction to heroin. However, it is less well known that his son, William S. Burroughs Junior, published two autobiographical novels (Speed and Kentucky Ham; Burroughs Jr, 1970, 1973) documenting his addiction to amphetamines and, later, heroin.

Burroughs Junior was clearly at high risk of developing problems of addiction as both of his parents were dependent on psychoactive substances. Indeed, in 1951, aged just 4 years, he was said to have been in the room when his father accidentally shot his mother. Burroughs Junior ultimately died, aged 34, of liver failure. Another important American author in this genre is Hubert Selby Junior, author of Last Exit to Brooklyn (Selby Jr, 1987). His novel Requiem for a Dream (Selby Jr, 1979) links four characters in a story of drug addiction that leads to imprisonment, death, prostitution and incarceration in a mental hospital. The main agent of destruction for the three younger characters is heroin, but this is ultimately seen as no different from the effects of prescription drugs used by the mother of one of them.

The novel was recently made into a compelling film of the same name, directed by Darren Aronofsky, with Selby Junior providing the screenplay and also appearing in a cameo role as a prison guard, laughing at the predicament of the two male characters. Much of Selby Junior's other work touches on issues related to addiction and degradation.

\section{Doctors and addiction}

How do addicted patients view their doctors? A literary insight is given by William Burroughs in Junky (1977), written at a time when doctors were the main source of heroin. He describes them disparagingly as 'croakers' and gives advice on how best to approach them in order to achieve the addict's goal of receiving a prescription. He prefers a convincing story that allows the doctor to save face in writing the prescription rather than a 'factual approach' and advises the reader that 'you need a good bedside manner with doctors or you will get nowhere' (Burroughs, 1997: p. 21). Although this account was written in the American context and before the current vogue for substitute prescribing, there are still lessons to be learned from it. Our patients who are addicted present us with stories that are designed to induce a desired response, whatever that might be.
There are few literary accounts of doctors who successfully help patients with addiction to overcome their problems, perhaps reflecting the reality that recovery is about self-discovery. Research suggests that the impact of treatment is modest in the long term and that recovery is about the individual constructing a new identity that does not revolve around drugs or alcohol and acknowledging the need to abstain. One exception is the writer Eugene O'Neill who, after many failed attempts at recovery from his heavy alcohol use, sustained prolonged abstinence after psychoanalysis (Ludwig, 1988).

In contrast, many accounts exist of unscrupulous doctors who produce addiction in their patients. An excellent example of this is the doctor in Hubert Selby Junior's Requiem for a Dream (Selby Jr, 1979). Not only does the doctor lead the mother whose son is addicted to street drugs into dependence on diet pills, but then he tries to counteract her descent into psychosis with tranquillisers, giving little time or thought to the consequences of the prescription.

Doctors who have themselves become impaired through the use of drugs and alcohol frequently appear in literature. Drug and alcohol misuse are, in fact, the most common reasons for doctors in the UK to come to the attention of the Health Committee of the General Medical Council, and perhaps this literary concern reflects not only reality but also an interest in the complexity of character found in such individuals. Although he was unable to accept his own problem with alcohol, in Tender is the Night, Fitzgerald wrote memorably about the psychiatrist, Dick Diver, and his descent into alcoholism. There are also some notable short stories on this theme, including Mikhail Bulgakov's Morphine in A Country Doctor's Notebook (Bulgakov, 1975). This is a warning against the perils of self-medicating with drugs and the addictive process that might ensue, as the doctor, Polyakov, ultimately commits suicide. Finally, Verghese's The Tennis Partner (1998) is a personal narrative by an American physician who becomes aware of an addictive disorder in a junior colleague who is an ex-tennis professional. The author relates the problem of addiction in the medical profession to the expectation that doctors should conceal their own emotions and to the possibility that vulnerable individuals can be left in a position of isolation.

\section{Conclusions}

This short review is, by necessity, highly selective in its choice of examples, and space limitations have prevented us including other important addictive processes such as smoking, gambling and 'sex addiction'. However, we hope that we have shown 
that literature is capable of broadening our perspective on the phenomena of addiction and substance use. Modern diagnostic concepts and operational definitions of misuse and dependence tend to simplify a complex problem, and literary accounts help us to regain the perspective of the highly individual experience of using the different classes of psychoactive drugs. Furthermore, we have touched on new qualitative research on addicts' own narratives of their dependence which appears to complement this literary perspective. Finally, we have warned against taking too seriously the claims made by some authors of drug-enhanced creativity and also found literary warnings of our own vulnerabilities, as doctors, to addictive disorders.

\section{References}

Adams, T. (1998) Addicted. London: CollinsWillow.

Andreasen, N. C. (1987) Creativity and mental illness: prevalence rates in writers and their first-degree relatives. American Journal of Psychiatry, 144, 1288-1292.

Barber, L. (2000) Self control. The Observer. 11 June (http:// books.guardian.co.uk/departments / generalfiction/ story / 0,6000,330140,00.html)

Beard, R. (1996) X20. London: Flamingo.

Beveridge, A. \& Yorston, G. (1999) I drink, therefore I am: alcohol and creativity. Journal of the Royal Society of Medicine, 92, 646-648.

Bold, A. (ed.) (1982) Drink to Me Only: The Prose (and Cons) of Drinking. London: Robin Clark.

Bulgakov, M. (1975) A Country Doctor's Notebook (trans. M. Glenny) London: Collins \& Harvill.

Burgess, M. (1999) Junk. London: Penguin Books.

Burroughs, W. S. (1977) Junky. London: Penguin Books.

- (1986) The Naked Lunch. London: Flamingo.

Burroughs Jr., W. S. (1970) Speed. New York: Overlook Press.

- (1973) Kentucky Ham. New York: Overlook Press.

Coleridge, S. T. (1992) Poetical Works. Oxford: Oxford University Press.

Collins, W. (1999) The Moonstone. Oxford: Oxford Paperbacks.

Dardis, T. (1989) The Thirsty Muse: Alcohol and the American Writer. New York: Ticknor \& Fields.

Davidson, T. (ed.) (1998) Intoxication: an Anthology of Stimulant-based Writing. London: Serpent's Tail.

Davies, J. B. (1997) The Myth of Addiction (2nd edn). Amsterdam: Harwood Academic Publishers.

De Quincey, T. (1986) Confessions of an English Opium Eater. London: Penguin Books.

Edwards, G. (2000) Alcohol. The Ambiguous Molecule. London: Penguin Books.

Eynon, T. (2002) Cognitive linguistics. Advances in Psychiatric Treatment, 8, 399-407.

Fitzgerald, F. S. (1965) The Crack-Up and Other Stories. London: Penguin Books.

- (1993) The Great Gatsby. London: Wordsworth Editions.

- (1994) Tender is The Night. London: Wordsworth Editions.

- (2002) The Last Tycoon. Harmondsworth: Penguin Books.
Goodwin, D. W. (1988) Alcohol and the Writer. Kansas City: Andrews and McMeel.

Haining, P. (1998) The Walls of Illusion: a Psychedelic Retro. London: Souvenir Press.

Hanninen, V. \& Koski-Jannes, A. (1999) Narratives of recovery from addictive behaviour. Addiction, 94, 1837-1848.

Hayter, A. (1968) Opium and the Romantic Imagination. London: Faber \& Faber.

Huxley, A. (1994) The Doors of Perception. London: Flamingo. Jay, M. (ed.) (1999) Artificial Paradises. London: Penguin Books.

Knapp, C. (1996) Drinking: A Love Story. London: Quartet Books.

Ludwig, A. M. (1988) Understanding the Alcoholic's Mind. New York: Oxford University Press.

Marks, H. (ed.) (2001) The Howard Marks Book of Dope Stories. London: Vintage.

Marlowe, A. (1999) How to Stop Time: Heroin from A to Z. London: Virago Press.

McIntosh, J. \& McKeganey, N. (2000) Addicts' narratives of recovery from drug use: constructing a non-addict identity. Social Science and Medicine, 50, 1501-1510.

Melechi, A. (ed.) (1997) Psychedelia Britannica. London: Turnaround.

- (1998) Mindscapes: an Anthology of Drug Writings. Baildon: Mono.

Miller, J. \& Koral, R. (eds) (1995) White Rabbit: a Psychedelic Reader. San Francisco, CA: Chronicle Books.

Nietzsche, F. (1990) Twilight of the Idols (Trans. R. J. Hollingdale). Harmondsworth: Penguin.

Plant, S. (1999) Writing on Drugs. London: Faber \& Faber.

Post, F. (1994) Creativity and psychopathology. A study of 291 world-famous men. British Journal of Psychiatry, 165, $22-34$.

- (1996) Verbal creativity, depression and alcoholism. An investigation of one hundred American and British writers. British Journal of Psychiatry, 168, 545-555.

Rae, S. (ed.) (1991) The Faber Book of Drink, Drinkers and Drinking. London: Faber and Faber.

Riley, G. (1992) How to Stop Smoking and Stay Stopped for Good. London: Vermilion.

Roth, J. (2000) The Legend of the Holy Drinker (trans. M. Hofmann). London: Granta.

Rudgley, R. (ed.) (2001) Wildest Dreams: an Anthology of DrugRelated Literature. London: Abacus.

Rushkoff, D. (1997) The Ecstasy Club. London: Sceptre.

Selby Jr., H. (1979) Requiem for a Dream. London: Marion Boyars.

- (1987) Last Exit to Brooklyn. London: Flamingo.

Shell, R. (1993) Iced. London: Flamingo.

Shelley, M. (1992) Frankenstein (ed. M. Hindle). London: Penguin Books.

Sounes, H. (1998) Charles Bukowski: Locked in the Arms of a Crazy Life. Edinburgh: Rebel.

Strausbaugh, J. \& Blaise, D. (eds) (1991) The Drug User: Documents 1840-1960. New York: Blast Books.

Strongman, P. (1997) Cocaine. London: Abacus.

Sutherland, J. (1998) Turns unstoned. Times Literary Supplement, 30 October.

- (2001) Last Drink to LA. London: Short Books.

Verghese, A. (1998) The Tennis Partner: A Doctor's Story of Friendship and Loss. London: Chatto \& Windus.

Welsh, I. (1999) Trainspotting. London: Vintage.

Yablonsky, L. (1997) The Story of Junk. London: Headline Publishing. 